\title{
Reliabilitas Suatu Mesin Menggunakan Rantai Markov (Studi Kasus: Mesin Proofer Di Pabrik Roti Super Jam Banten)
}

\author{
Mega Novia Andriani ${ }^{1}$, Firdaniza $^{2}$, ,in Irianingsih $^{3}$ \\ ${ }^{1,2,3}$ Departemen Matematika FMIPA Universitas Padjadjaran \\ Jl. Raya Bandung-Sumedang Km 21 Jatinangor 45363 \\ Email: firdaniza@unpad.ac.id
}

\begin{abstract}
ABSTRAK
Mesin merupakan alat vital perusahaan dalam membantu proses produksi. Setiap perusahaan mengharapkan proses produksi berjalan dengan lancar, tetapi terkadang terkendala dengan terjadinya kerusakan pada mesin, sehingga proses produksi terganggu dan menyebabkan kerugian bagi perusahaan. Kerusakan pada mesin dapat diminimalisir dengan melakukan evaluasi terhadap kondisi mesin tersebut secara teratur. Penelitian ini menggunakan rantai Markov untuk mengetahui peluang jangka panjang kondisi suatu mesin dan menganalisis reliabilitas dari mesin tersebut untuk memperkirakan waktu perawatan. Studi kasus dilakukan pada mesin Proofer di Pabrik Roti Super Jam Banten mulai tanggal 3 Maret 2014 sampai tanggal 31 Mei 2015. Dari penelitian ini diperoleh hasil bahwa peluang jangka panjang mesin Proofer dalam kondisi baik adalah $42,86 \%$ dan disarankan untuk melakukan perawatan rutin pada mesin tersebut minimal setiap 22 hari sekali.
\end{abstract}

Kata kunci: mesin, rantai markov, reliabilitas.

\section{ABSTRACT}

A Machine is a vital tool in helping the company's production process. Each company expects the production process runs smoothly, but sometimes hampered by damage to the machine, so the production process is disrupted and cause losses for the company. The damage to the machine can be minimized by evaluating the condition of the machine regularly. This research used a Markov chain to determine the longterm probability of the condition of a machine and analyze the reliability of these machines to estimate treatment time. The case studies carried out on the machine Proofer at Super Jam Banten Bread Factory from the March 3, 2014 until May 31, 2015. From this study showed that long-term probability Proofer machine in good condition is $42.86 \%$ and it is advisable to perform routine maintenance on the machine at least once every 22 days.

Keywords: machine, markov chain, reliability.

\section{Pendahuluan}

Mesin merupakan salah satu aspek terpenting dalam bidang industri manufaktur maupun industri jasa. Dalam kegiatan produksi, sangat diharapkan proses berlangsung secara lancar. Jika terdapat gangguan pada mesin maka kegiatan produksipun harus terhenti, sehingga produk yang dihasilkan tidak optimal dan menimbulkan kerugian bagi perusahaan. Kerusakan pada mesin dapat terjadi karena adanya human error, kurangnya perawatan dan sebagainya. Untuk mengevaluasi kondisi mesin diperlukan analisis rantai Markov untuk menentukan peluang jangka panjang dari kondisi mesin tersebut. Tingkat keandalan mesin yang rendah mengakibatkan kerugian bagi perusahaan dan kemungkinan membahayakan pekerja, sehingga diperlukan suatu pengukuran dan analisis tingkat keandalan atau reliabilitas suatu mesin untuk membantu perusahaan agar melakukan tindakan perawatan yang teratur.

Berdasarkan waktu, dalam menentukan nilai reliabilitas suatu mesin dapat dilakukan dengan metode reliabilitas menggunakan rantai Markov kontinu; Sadek et.al, [4] dan metode reliabilitas menggunakan rantai Markov diskrit;Sadek et al, [5]. Dalam menentukan reliabilitas mesin, Sadek, et.al [5] tidak 
menganalisis secara rinci apakah rantai Markov merupakan rantai Markov ergodik atau tidak. Pada paper ini dibahas metode reliabilitas dengan menggunakan analisis rantai Markov diskrit secara rinci, dan selanjutnya metode tersebut diterapkan pada data total waktu kerusakan mesin proofer.

\section{Metode Penelitian}

Pada penelitian ini dilakukan kajian tentang rantai Markov ergodik, sebagai syarat untuk memperoleh peluang jangka panjang kondisi mesin serta menentukan nilai reliabilitas suatu mesin menggunakan rantai Markov.

\subsection{Rantai Markov Diskrit}

Misal $\{X(n), n=0,1,2, \ldots$.$\} proses stokastik dengan indeks parameter T$ diskrit dan ruang keadaan $S$ memenuhi

$$
P\left\{X(n+1)=j \mid \begin{array}{c}
X(0)=i_{0}, X(1)=i_{1}, X(2) \\
=i_{2}, \ldots, X(n-1)=i_{n-1}, X(n)=i
\end{array}\right\}=P\{X(n+1)=j \mid X(n)=i\}=p_{i j}
$$

untuk semua waktu $n \in T$ dan keadaan $i_{0}, i_{1}, \ldots, i, j \in S$, maka proses tersebut disebut rantai Markov waktu diskrit, dan $p_{i j}$ disebut peluang transisi;Osaki [3].

Matriks peluang transisi $\mathbf{P}$ satu langkah didefinisikan sebagai berikut:

$$
\mathbf{P}=\left[p_{i j}\right]=\left[\begin{array}{cccc}
p_{00} & p_{01} & p_{02} & \ldots \\
p_{10} & p_{11} & p_{12} & \ldots \\
p_{20} & p_{21} & p_{22} & \ldots \\
\vdots & \vdots & \vdots & p_{i j}
\end{array}\right]
$$

dengan $p_{i j} \geq 0$ dan $\sum_{j=0}^{\infty} p_{i j}=1(i, j=0,1,2, \ldots) ;$ Osaki[3].

Suatu keadaan $j$ dikatakan dapat dicapai dari keadaan $i$, jika untuk $n \geq 0$ maka $p_{i j}^{n}>0$, dinotasikan $i \rightarrow j$, dan setiap keadaan dapat dicapai oleh dirinya sendiri, dinotasikan $i \rightarrow i$, karena $\quad p_{i i}^{0}=1$. Keadaan $i$ dan $j$ dikatakan saling berkomunikasi jika $i \rightarrow j$ dan $j \rightarrow i$, dinotasikan dengan $i \leftrightarrow j$, artinya untuk bilangan bulat $m \geq 0$ dan $n \geq 0$ maka $p_{i j}^{m}>0$ dan $p_{j i}^{n}>0$.

Definisi 1. Untuk suatu rantai Markov, jika hanya terdapat satu kelas komunikasi maka dinamakan rantai Markov yang irreducible. Artinya untuk rantai Markov irreducible, semua keadaan saling berkomunikasi satu sama lain ;Osaki[3].

Teorema 2. Keadaan i dikatakan recurrent jika dan hanya jika $\sum_{n=1}^{\infty} p_{i i}^{n}=\infty$. Keadaan i dikatakan transient jika dan hanya jika $\sum_{n=1}^{\infty} p_{i i}^{n}<\infty$;Osaki [3].

Teorema 3. Jika keadaan $i$ adalah recurrent dan $i \leftrightarrow j$, maka keadaan $j$ adalah recurrent; Osaki [3].

Definisi 4. Keadaan $i$ memiliki periode $d(i)$, apabila $d(i)$ merupakan faktor persekutuan terbesar (FPB) dari $n$, untuk semua bilangan bulat $n \geq 1$ dimana $p_{i i}^{n}>0$.

$$
d(i)=\operatorname{FPB}\left\{n \geq 1 \mid p_{i i}^{n}>0\right\}
$$

Jika $d(i)=1$, keadaan $i$ adalah aperiodik, dan jika $d(i)>1$, keadaan $i$ adalah periodik ; Osaki[3].

Teorema 5. Jika $i \leftrightarrow j \operatorname{maka}(i)=d(j)$; Osaki[3].

Definisi 6. Untuk suatu rantai Markov, semua keadaan recurrent diklasifikasikan menjadi positive (non-null) recurrent atau null recurrent dilihat dari $\mu_{j}<\infty$ atau $\mu_{j}=\infty$ dimana

$$
\mu_{j}=\sum_{n=1}^{\infty} n f_{j j}^{n}
$$

menyatakan rata-rata waktu recurrent untuk keadaan $j$; Osaki[3]. Rantai Markov dikatakan ergodik jika rantai markov tersebut positive recurrent dan aperiodik ; Osaki[3].

Teorema 7. Jika keadaan $j$ adalah recurrent dan aperiodik, maka $p_{j j}^{n} \rightarrow \frac{1}{\mu_{j}}$, untuk $n \rightarrow \infty$ diinterpretasikan $\frac{1}{\mu_{j}}=0$ jika $\mu_{j}=\infty ;$ Osaki[3]. 
Teorema 8. Jika suatu rantai Markov adalah irreducible dan ergodik, maka terdapat limit peluang

$$
\lim _{n \rightarrow \infty} p_{i j}^{n}=\pi_{j}, i, j=0,1,2
$$

yang tidak tergantung pada keadaan awal $i$, dimana $\left\{\pi_{j}, j=0,1,2, \ldots\right\}$ adalah distribusi stasioner dari rantai Markov solusi unik dan positif dari $\pi_{j}=\sum_{i=0}^{\infty} \pi_{i} p_{i j}, j=0,1,2, \ldots$, dengan $\sum_{j=0}^{\infty} \pi_{j}=1 ;$ Osaki[3].

\subsection{Reliabilitas Menggunakan Rantai Markov}

Definisi 9. Diberikan ruang keadaan terbatas $S=\{0,1, \ldots, s\}$, dipartisi menjadi dua bagian, $U=$ $\{0,1, \ldots, r\}$ untuk keadaan bekerja (up state) dan $D=\{r+1, \ldots, s\}$ untuk keadaan yang gagal (down state). Artinya $S=U \cup D, U \cap D=\varnothing$ dan $U \neq \emptyset, D \neq \emptyset$. Diberikan $\left\{X_{n}\right\}, n=0,1, \ldots, m$ rantai Markov yang ergodik dengan keadaan terbatas $S=\{0,1, \ldots, s\}$, maka reliabilitas berdasarkan rantai Markov $\left\{X_{n}\right\}$ pada waktu $n \geq 0$ didefinisikan

$$
R(n)=P\left(\forall v \in[0, n] \cap \mathbb{N}, X_{v} \in U\right)
$$

dimana $v$ merupakan indeks waktu untuk periode tertentu; Balakrishnan [1]

Untuk $n=0$, mesin dalam kondisi sangat baik dan belum pernah mengalami kerusakan sama sekali, artinya tingkat keandalan atau reliabilitas dari suatu mesin tersebut sangat baik sehingga $R(0)=1$.

Dengan memandang partisi keadaan $U$ dan $D$ maka matriks peluang transisi $\mathbf{P}$ dan distribusi awal $\pi(0)$ menjadi

$\mathbf{P}=\left[\begin{array}{ll}\mathbf{P}_{U U} & \mathbf{P}_{U D} \\ \mathbf{P}_{D U} & \mathbf{P}_{D D}\end{array}\right]$ dan $\pi(0)=\left[\pi_{U}(0), \pi_{D}(0)\right]$

Maka reliabilitas untuk rantai Markov didefinisikan sebagai berikut:

$$
R(n)=\pi_{u}(0) \mathbf{P}_{U U}^{n} 1_{r} \text { untuk } \geq 0 ; \text { Balakrishnan[1]. }
$$

\section{Hasil dan Pembahasan}

Dari data total waktu kerusakan mesin proofer di pabrik roti Super Jam Banten mulai dari tanggal 3 Maret 2014 sampai dengan 31 Mei 2015 dibuat pengelompokan waktu untuk mendefinisikan keadaan sebagai berikut:

Misalkan twk menyatakan total waktu kerusakan mesin.

(i) Jika $t w k=0$ maka mesin dikategorikan dalam kondisi baik, diberi simbol angka 0 , yang menyatakan keadaan 0 .

(ii) Jika $0<t w k<4$ maka mesin dikategorikan dalam kondisi rusak ringan, diberi simbol angka 1 , yang menyatakan keadaan 1 .

(iii) Jika $4 \leq t w k \leq 7$ maka mesin dikategorikan dalam kondisi rusak parah, diberi simbol angka 2 , yang menyatakan keadaan 2 .

Maka ruang keadaan untuk keadaan di atas adalah $S=\{0,1,2\}$.

Setiap perpindahan keadaan (transisi) dari kondisi mesin proofer dikelompokkan ke dalam tabel jumlah transisi dari keadaan $i$ ke keadaan $j$ dengan $i, j=0,1,2$, dimana 0 adalah keadaan baik, 1 adalah keadaan rusak ringan dan 2 adalah keadaan rusak parah, yang terlihat pada Tabel 1.

Tabel 1. Jumlah transisi keadaan $i$ ke keadaan $j$ dari data total waktu kerusakan mesin proofer

\begin{tabular}{|c|c|c|c|c|}
\hline$i$ & $\begin{array}{c}0 \\
\text { (Baik) }\end{array}$ & $\begin{array}{c}1 \\
\text { (Rusak ringan) }\end{array}$ & $\begin{array}{c}2 \\
\text { (Rusak parah) }\end{array}$ & Jumlah \\
\hline $\begin{array}{c}0 \\
\text { (Baik) }\end{array}$ & 94 & 63 & 38 & 195 \\
\hline $\begin{array}{c}1 \\
\text { (Rusak ringan) }\end{array}$ & 101 & 61 & 30 & 192 \\
\hline $\begin{array}{c}2 \\
\text { (Rusak parah) }\end{array}$ & 0 & 66 & 0 & 66 \\
\hline Jumlah & 195 & 190 & 68 & 453 \\
\hline
\end{tabular}


Selanjutnya Tabel 1 dibuat ke dalam bentuk matriks peluang transisi seperti persamaan (2), diperoleh:

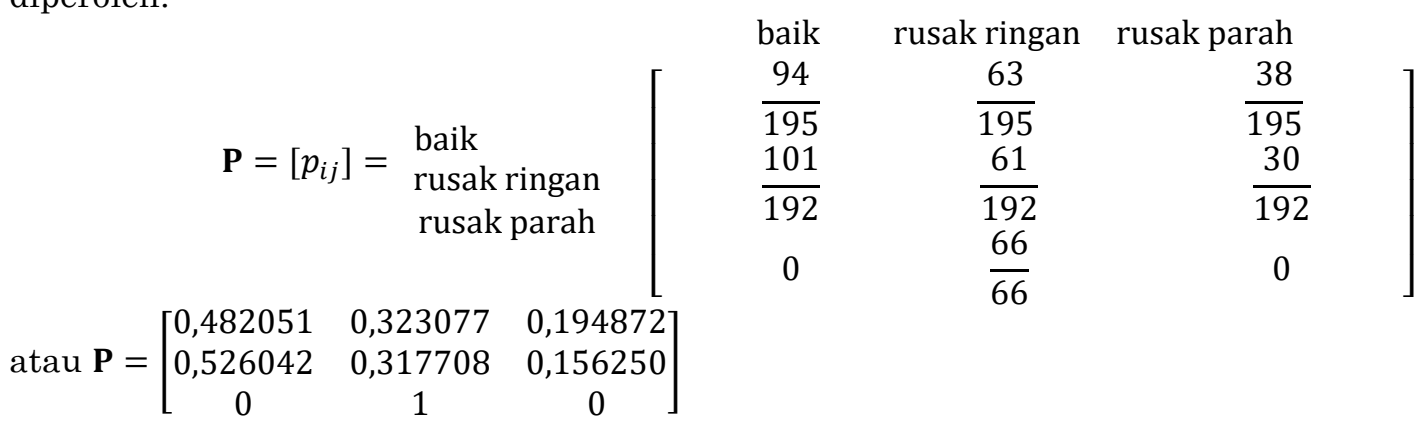

Selanjutnya matriks peluang transisi $\mathbf{P}$ dibuat ke dalam diagram transisi

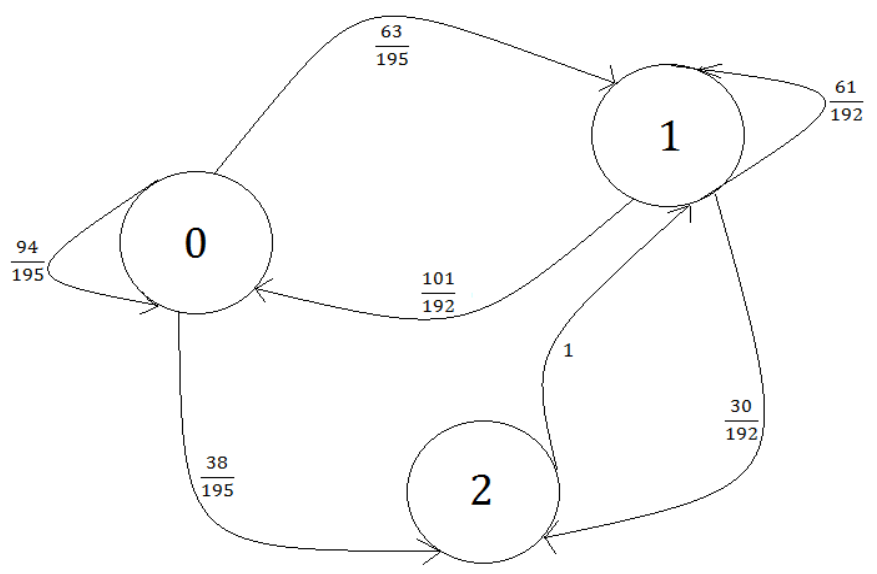

Gambar 1. Diagram transisi dari matriks peluang transisi $\mathbf{P}$

Dilihat dari Gambar 1 semua keadaan saling berkomunikasi dan berada dalam satu kelas yang sama yaitu kelas $\{0,1,2\}$, berdasarkan definisi 1 maka rantai Markov tersebut adalah irreducible.

Selanjutnya dihitung matriks peluang transisi $\mathbf{P}$ hingga $n$ langkah sebagai berikut:

$$
\begin{aligned}
\mathbf{P}^{1} & =\left[\begin{array}{lll}
0,482051 & 0,323077 & 0,194872 \\
0,526042 & 0,317708 & 0,156250 \\
0 & 1 & 0
\end{array}\right] \\
\mathbf{P}^{2} & =\left[\begin{array}{lll}
0,402325 & 0,453256 & 0,144419 \\
0,420707 & 0,427140 & 0,152153 \\
0,526042 & 0,317708 & 0,156250
\end{array}\right] \\
\mathbf{P}^{3} & =\left[\begin{array}{lll}
0,432373 & 0,418404 & 0,149223 \\
0,427496 & 0,423779 & 0,148725 \\
0,420707 & 0,427140 & 0,152153
\end{array}\right] \\
\mathbf{P}^{4} & =\left[\begin{array}{lll}
0,428524 & 0,421843 & 0,149633 \\
0,429001 & 0,421477 & 0,149522 \\
0,427496 & 0,423779 & 0,148725
\end{array}\right]
\end{aligned}
$$

Pertama diperiksa apakah rantai Markov dengan matriks peluang transisi $\mathbf{P}$ recurrent atau transient dengan teorema 2 ,

Untuk keadaan 0

$$
\begin{aligned}
\sum_{n=1}^{\infty} p_{00}^{n} & =p_{00}^{1}+p_{00}^{2}+p_{00}^{3}+p_{00}^{4}+\cdots \\
& =0,482051+0,402325+0,432373+0,428524+\cdots=\infty .
\end{aligned}
$$

karena $\sum_{n=1}^{\infty} p_{00}^{n}=\infty$, maka menurut Teorema 2 keadaan 0 adalah recurrent. 
Selanjutnya untuk keadaan 1 dan 2 karena $0 \leftrightarrow 1,0 \leftrightarrow 2$ dan keadaan 0 recurrent, maka menurut Teorema 3, keadaan 1 dan 2 recurrent. Jadi setiap keadaan adalah recurrent. Selanjutnya diperiksa periodisitas setiap keadaan dengan persamaan (3).

Pertama akan diperiksa untuk keadaan 0 .

$n=1 \rightarrow p_{00}^{1}=0.482051>0$

$n=2 \rightarrow p_{00}^{2}=0.402325>0$

$n=3 \rightarrow p_{00}^{3}=0.432373>0$

$n=4 \rightarrow p_{00}^{4}=0.428524>0$

Sehingga $d(0)=\operatorname{FPB}\{2,3,4,5, \ldots\}=1$. Karena $d(0)=1$, maka menurut definisi 4 keadaan 0 aperiodik.

Selanjutnya untuk keadaan 1 dan keadaan 2, berdasarkan teorema 5 karena $0 \leftrightarrow 1$ dan $0 \leftrightarrow 2$ maka berlaku $d(1)=d(0)=d(2)=1$. Sehingga keadaan 1 dan keadaan 2 aperiodik.

Selanjutnya diperiksa apakah setiap keadaan positive recurrent atau null-recurrent. Dengan menggunakan program Maple 2015 diperoleh matriks dengan nilai yang sama untuk entri-entri setiap kolomnya pada saat dipangkatkan sebanyak 22 kali.

$\mathbf{P}^{22}=\left[\begin{array}{lll}0,428571 & 0,421978 & 0,149451 \\ 0,428571 & 0,421978 & 0,149451 \\ 0,428571 & 0,421978 & 0,149451\end{array}\right]$

Setelah itu, diperiksa apakah setiap keadaan tersebut adalah positive recurrent atau null recurrent, karena setiap keadaan bersifat recurrent dan aperiodik, maka menurut teorema 7 diperoleh

Untuk keadaan 0

$p_{00}^{n} \rightarrow \frac{1}{\mu_{0}}=0,428571$, maka $\mu_{0}=2,333336$.

Untuk keadaan 1

$p_{11}^{n} \rightarrow \frac{1}{\mu_{1}}=0,421978$, maka $\mu_{1}=2,369792$.

Untuk keadaan 2

$p_{22}^{n} \rightarrow \frac{1}{\mu_{2}}=0,149451$, maka $\mu_{2}=6,691156$.

Karena $\mu_{0}=2,333336<\infty, \mu_{1}=2,369792<\infty$ dan $\mu_{2}=6,691156<\infty$, menurut definisi 6 maka keadaan 0 , keadaan 1 dan keadaan 2 adalah positive recurrent.

Karena setiap keadaan adalah positive recurrent dan aperiodik, maka rantai Markov tersebut ergodik dan irreducible.

Selanjutnya dicari peluang jangka panjang dari rantai Markov dengan matriks peluang transisi $\mathbf{P}$. Berdasarkan teorema 8, dengan menggunakan Maple 2015 diperoleh peluang jangka panjang dari rantai Markov dengan matriks peluang transisi $\mathbf{P}$ sebagai berikut:

$\lim _{n \rightarrow \infty} p_{i 0}^{n}=\pi_{0}=0,428571, i=0,1,2$.

$\lim _{n \rightarrow \infty} p_{i 1}^{n}=\pi_{1}=0,421978, i=0,1,2$.

$\lim _{n \rightarrow \infty} p_{i 2}^{n}=\pi_{2}=0,149451, i=0,1,2$.

Sehingga peluang jangka panjang untuk rantai Markov dengan matriks peluang transisi $\mathbf{P}$ adalah

$$
\boldsymbol{\pi}=\left[\pi_{0}, \pi_{1}, \pi_{2}\right]=[0,428571,0,421978,0,149451]
$$

Artinya untuk jangka panjang, peluang mesin proofer dalam kondisi baik adalah $42,86 \%$, peluang mesin proofer dalam kondisi rusak ringan adalah $42,20 \%$, dan peluang mesin proofer dalam kondisi rusak berat adalah $14,94 \%$.

Berdasarkan asumsi penentuan simbol keadaan, diketahui ruang keadaan untuk kondisi mesin proofer di pabrik roti Super Jam Banten ini adalah $S=\{0,1,2\}$ dan diasumsikan keadaan awal mesin adalah dalam kondisi baik. Selanjutnya ruang keadaan $S$ dipartisi menjadi dua bagian, yaitu 
keadaan bekerja $U$ dan keadaan gagal $D$. Kondisi yang termasuk dalam keadaan gagal (down state) adalah kondisi dimana suatu mesin tidak berfungsi untuk waktu yang lama (downtime); $\mathrm{Mu}$ [2], maka berdasarkan asumsi dalam pengklasifikasian total waktu kerusakan pada mesin proofer yang termasuk dalam keadaan bekerja yaitu $U=\{0,1\}$ dan keadaan gagal yaitu $D=\{2\}$. Selanjutnya dicari nilai reliabilitas dengan menggunakan persamaan (7)

$R(n)=\pi_{u}(0) \mathbf{P}_{U U}^{n} 1_{r}$.

Dengan menggunakan partisi tersebut, ruang keadaan $U=\{0,1\}$ disubtitusikan ke persamaan (7) sehingga diperoleh

$R(n)=\left[\pi_{0}(0) \pi_{1}(0)\right]\left[\begin{array}{ll}p_{00} & p_{01} \\ p_{10} & p_{11}\end{array}\right]^{n}\left[\begin{array}{l}1 \\ 1\end{array}\right]$

Pertama dicari nilai reliabilitas untuk $n=1$,

$$
\begin{aligned}
R(1) & =\left[\begin{array}{ll}
1 & 0
\end{array}\right]\left[\begin{array}{ll}
0,482051 & 0,323077 \\
0,526042 & 0,317708
\end{array}\right]^{1}\left[\begin{array}{l}
1 \\
1
\end{array}\right] \\
& =\left[\begin{array}{ll}
1 & 0
\end{array}\right]\left[\begin{array}{ll}
0,482051 & 0,323077 \\
0,526042 & 0,317708
\end{array}\right]\left[\begin{array}{l}
1 \\
1
\end{array}\right] \\
& =\left[\begin{array}{ll}
0,482051 & 0,323077
\end{array}\right]\left[\begin{array}{l}
1 \\
1
\end{array}\right] \\
& =0,482051+0,323077 \\
& =0,805128
\end{aligned}
$$

maka nilai reliabilitas untuk $n=1$ adalah 0,805128 , artinya pada hari ke- 1 peluang mesin proofer tersebut menjalankan fungsinya dengan baik adalah $80,51 \%$.

Selanjutnya berdasarkan rantai Markov yang telah diperoleh peluang jangka panjangnya maka dengan cara yang sama, dicari nilai reliabilitas untuk $n=2,3,4, \ldots, 22$. Hasil perhitungan dapat dilihat pada tabel 2 berikut.

Tabel 2. Nilai reliabilitas mesin proofer pabrik roti Super Jam Banten

\begin{tabular}{|c|c|c|c|c|c|}
\hline$n$ & $R(n)$ & $n$ & $R(n)$ & $n$ & $R(n)$ \\
\hline 2 & 0,660709 & 9 & 0,165043 & 16 & 0,041228 \\
\hline 3 & 0,541935 & 10 & 0,135375 & 17 & 0,033817 \\
\hline 4 & 0,444517 & 11 & 0,111040 & 18 & 0,027738 \\
\hline 5 & 0,364612 & 12 & 0,091080 & 19 & 0,022752 \\
\hline 6 & 0,299066 & 13 & 0,074708 & 20 & 0,018662 \\
\hline 7 & 0,245309 & 14 & 0,061278 & 21 & 0,015307 \\
\hline 8 & 0,201213 & 15 & 0,050263 & 22 & 0,012556 \\
\hline
\end{tabular}

Nilai reliabilitas (tingkat keandalan) mesin Proofer di Pabrik Roti Super Jam dengan matriks peluang transisi $\mathbf{P}$ untuk 22 hari, dapat dilihat seperti Gambar 2.

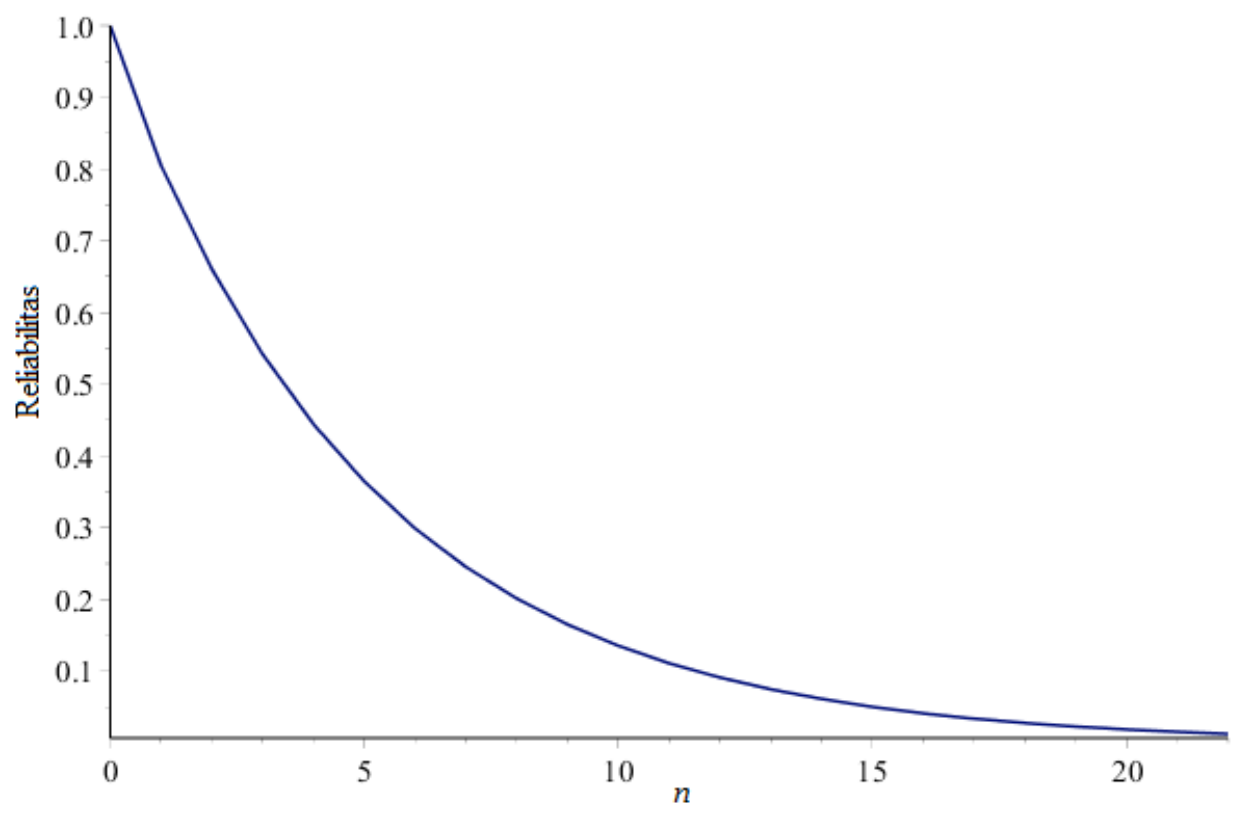

Gambar 2. Grafik reliabilitas mesin proofer di pabrik roti Super Jam 
Dilihat dari Gambar 2, reliabilitas (tingkat keandalan) dari mesin proofer tersebut menurun setiap harinya. Pada saat hari ke-22 tingkat keandalan dari mesin proofer tersebut adalah 1,26\%. Sehingga disarankan agar perusahaan melakukan perawatan rutin pada mesin tersebut minimal 22 hari sekali.

\section{Simpulan}

Untuk jangka panjang, peluang mesin proofer dalam kondisi baik 42,86\% dan tingkat keandalan dari mesin proofer tersebut menurun setiap harinya. Pada hari ke-22, tingkat keandalan dari mesin proofer tersebut sudah sangat rendah. Sehingga disarankan agar perusahaan melakukan perawatan rutin minimal 22 hari sekali.

\section{Daftar Pustaka}

1. Balakrishnan. 2001. Handbook of Statistics, Vol. 20: Basic Probabilistic Models in Reliability. Elsevier Science.

2. $\mathrm{Mu}, \mathrm{D}$. 2008. Reliability and Availability Analysis of A Multistate Repairable System With Dependent Deteriorations and Redudancy.

3. Osaki, S. 1992. Applied Stochastic System Modeling. German: Springer-Verlag.

4. Sadek, A. and Limnios, N. 2005. Nonparametric Estimation of Reliability and Survival Function For Continuous-Time Finite Markov Processes, Journal of Statistical Planning and Inference 133 (2005) 1-21.

5. Sadek, A. and Ibraheem, B. 2010. Approximate Bayesian Estimation of Reliability for Multistate Markov Chain, Int. J. Contemp. Math. Sciences, Vol. 5, no. 1, 29-40. 